\title{
Article \\ Effect of Naturally Occurring Compounds on Fumonisin Production and fum Gene Expression in Fusarium verticillioides
}

\author{
Davide Ferrigo (D), Sharda Bharti, Massimiliano Mondin and Alessandro Raiola *(D) \\ Department of Land, Environment, Agriculture and Forestry-University of Padova, AGRIPOLIS—Viale \\ dell’Università 16, 35020 Legnaro, Italy; davide.ferrigo@unipd.it (D.F.); sharda.bharti@natec.unibz.it (S.B.); \\ massimiliano.mondin@unipd.it (M.M.) \\ * Correspondence: alessandro.raiola@unipd.it; Tel.: +39-0498272894
}

check for

updates

Citation: Ferrigo, D.; Bharti, S.; Mondin, M.; Raiola, A. Effect of Naturally Occurring Compounds on Fumonisin Production and fum Gene Expression in Fusarium verticillioides. Agronomy 2021, 11, 1060. https:/ / doi.org/10.3390/agronomy11061060

Academic Editors: Carla Ceoloni, Silvio Tundo and

Ljiljana Kuzmanović

Received: 14 April 2021

Accepted: 21 May 2021

Published: 25 May 2021

Publisher's Note: MDPI stays neutral with regard to jurisdictional claims in published maps and institutional affiliations.

Copyright: (c) 2021 by the authors. Licensee MDPI, Basel, Switzerland. This article is an open access article distributed under the terms and conditions of the Creative Commons Attribution (CC BY) license (https:// creativecommons.org/licenses/by/ $4.0 /)$.
Abstract: Fusarium verticillioides, one of the most common pathogens in maize, is responsible for yield losses and reduced kernel quality due to contamination by fumonisins (FBs). Two F. verticillioides isolates that differed in their ability to produce FBs were treated with a selection of eight natural phenolic compounds with the aim of identifying those that were able to decrease toxin production at concentrations that had a limited effect on fungal growth. Among the tested compounds, ellagic acid and isoeugenol, which turned out to be the most effective molecules against fungal growth, were assayed at lower concentrations, while the first retained its ability to inhibit toxin production in vitro, the latter improved both the fungal growth and FB accumulation. The effect of the most effective phenolic compounds on FB accumulation was also tested on maize kernels to highlight the importance of appropriate dosages in order to avoid conditions that are able to promote mycotoxin biosynthesis. An expression analysis of genes involved in FB production allowed more detailed insights into the mechanisms underlying the inhibition of FBs by phenolic compounds. The expression of the fum gene was generally down-regulated by the treatments; however, some treatments in the low-producing F. verticillioides strain up-regulated fum gene expression without improving FB production. This study showed that although different phenolic compounds are effective for FB reduction, they can modulate biosynthesis at the transcription level in opposite manners depending on strain. In conclusion, on the basis of in vitro and in vivo screening, two out of the eight tested phenols (ellagic acid and carvacrol) appear to be promising alternative molecules for the control of FB occurrence in maize.

Keywords: maize; Fusarium verticillioides; phenolic inhibitors; fumonisins; fum gene expression

\section{Introduction}

Fusarium verticillioides is the most common pathogenic fungus colonizing maize in Italy, and it is responsible for severe ear rot and the accumulation of mycotoxins in kernels. Fumonisins (FBs) are the main mycotoxins produced by F. verticillioides, and they represent a concern due to their toxicological implications, as their consumption can lead to serious disorders and mycotoxicosis in livestock [1] and cancer in humans [2]. Several approaches have been considered in order to reduce human and animal exposure to these mycotoxins, but pre-harvest control of this pathogen remains a goal for reducing FBs [3]. Control strategies against Fusarium spp. based on the use of synthetic fungicides could negatively affect the environment [4] and cause selective pressure on populations of these fungi, thus promoting the emergence of resistant strains [5]. For this reason, alternative management approaches, such as the development of natural fungicides or inhibitors of mycotoxin biosynthesis, appear to be promising.

Biological control agents can be used as sustainable alternative options in crop protection. Natural molecules that are able to reduce mycotoxin production could represent a further strategy to be investigated [6,7]. Naturally occurring phenolic compounds are metabolites that have become objects of increasing interest due to their biological properties 
against mycelial growth, germination, and production of conidia [8]; some of them are also involved in host resistance response [9].

Structurally, phenolic compounds are characterized by the presence of a hydroxyl group attached to an aromatic ring structure, and they can range from simple phenols to polyphenols $[10,11]$. Phenolic compounds activate mechanisms that interfere with pathogen growth and mycotoxin production, and it has mainly been suggested they can act through the modification of fungal lipid membrane permeability to cause the leakage of ions [8,12], acidification of cellular $\mathrm{pH}$, inhibition of biosynthetic enzymes, or modification of transcriptional regulation [13-15]. Further, other studies suggested that the antioxidant properties of these compounds could modulate mycotoxin production due to the quenching of the free radicals, which can reduce the upstream signals, such as ROS, which triggers or enhances biosynthesis of toxins by fungi $[16,17]$. Because a modification of the oxidative signals required to initialize mycotoxin synthesis $[18,19]$ is expected after treatment, the expression of three genes involved in FB biosynthesis (fum1 and fum19) and regulation (fum21) was surveyed. From a set of eight compounds (apocynin, caffeic acid, carvacrol, ellagic acid, ferulic acid, isoeugenol, propyl gallate, and vanillic acid), the present work aimed to identify those that had the best performance in interfering with the FB biosynthetic pathway, but with a low fungicidal effect in order to limit the risk of selection of more tolerant fungal populations. The data obtained in the present study provide insight into natural compounds that can display FB inhibitory capabilities and can function as alternative molecules for the control of Fusarium verticillioides and fumonisins.

\section{Materials and Methods}

\subsection{Fungal Strains}

A pool of Fusarium spp. colonies was isolated from maize kernels grown in Veneto by using the serial dilution method. Colonies that were morphologically identified as F. verticillioides [20]) were molecularly confirmed according to Mulè [21]. The cultures were subcultured on PDA (potato dextrose agar; BD/Difco, Sparks, MD, USA) for short-term storage or on SNA (Spezieller Nahrstoffarmer agar) for long-term storage and conidia production. Single-spore cultures were obtained according to Tuite [22]; one culture for each isolate was randomly selected and characterized on maize flour for its potential to produce FBs. Briefly, $10 \mathrm{~g}$ of maize flour (FB content $<200 \mathrm{ppb}$ ) was sterilized in a $94 \mathrm{~mm}$ glass Petri dish, soaked with $7.5 \mathrm{~mL}$ of sterile water, and inoculated in the center with a conidial suspension $\left(10^{6}\right.$ conidia). The procedure was carried out for each selected $F$. verticillioides strain. The cultures were incubated without shaking for 15 days in the dark at $25^{\circ} \mathrm{C}$ before FB quantification. Two F. verticillioides strains-termed H (high FB producer; $18,000 \mu \mathrm{g} / \mathrm{Kg}$ on ground maize) and L (low FB producer; $\sim 3000 \mu \mathrm{g} / \mathrm{Kg}$ on ground maize)—were selected for the studies and are hereafter called $F v \mathrm{H}$ and $F v \mathrm{~L}$, respectively. To perform all of the experiments, the cultures were grown for 15 days on SNA (Spezieller Nahrstoffarmer agar), and a conidial suspension was prepared with sterile water for $F v \mathrm{H}$ and $F v \mathrm{~L}$ to obtain a final concentration of $10^{6}$ conidia $/ \mathrm{mL}$.

\subsection{Tested Compounds}

Eight naturally occurring phenolic compounds (Figure 1) were selected to assess the effects of these chemicals on fungal growth and FB production. The selection of the compounds was based on their different antioxidant (TEAC; Trolox equivalent antioxidant capacity) and lipophilic $(\log P)$ properties (Table 1$)$. The selection was further guided by efficacy that the compounds demonstrated against other mycotoxigenic fungi $[8,23-25]$. The TEAC and $\log P$ values (Table 1 ) of each compound were reported on the basis of previous calculations [25-27]. The TEAC measures the ability of an antioxidant to scavenge oxidizable species, such as radicals. Lipophilicity represents the affinity of a compound for the lipid phase of plant tissues (membranes, waxes, cutin, suberin, etc.) and is a parameter linked to mobility in plants [28]. To improve solubilization and stability of the phenolic compounds in the growth medium [29], $\beta$-cyclodextrin CAVAMAX W7 Pharma 
( $\beta$-CD; Wacker Chemie Italia, Peschiera Borromeo, Italy) was used as a coadjutant in each experiment [30]. All of the compounds were purchased from Sigma Aldrich (Milan, Italy).

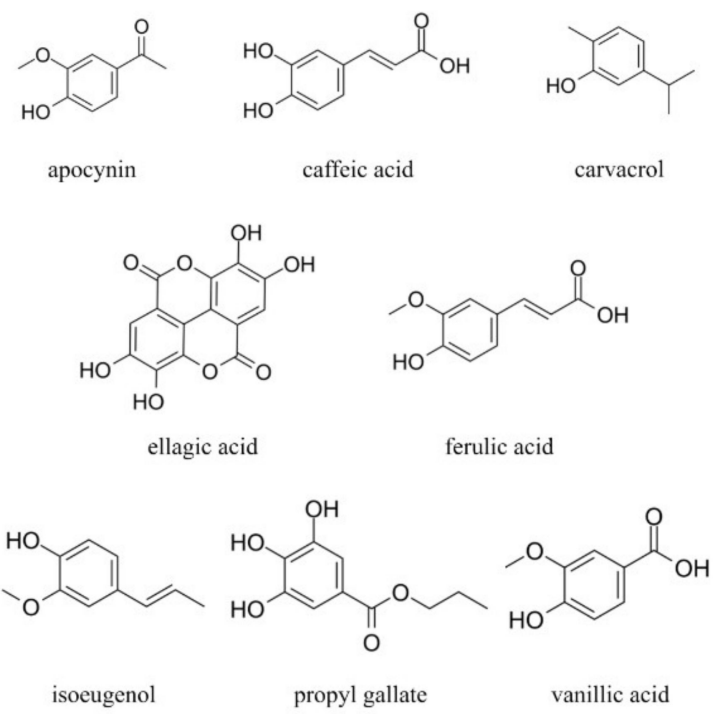

Figure 1. Structure of tested compounds.

Table 1. List of tested compounds listed according to antioxidant activity and lipophilicity.

\begin{tabular}{cccc}
\hline Compound Name & Type & TEAC $^{\mathbf{a}}$ & Lipophilicity Log P $^{\mathbf{b}}$ \\
\hline Apocynin (APO) & Acetophenones & 0.41 & 0.83 \\
Caffeic acid (CAF) & Cinnamic Acids & 1.25 & 1.15 \\
Carvacrol (CAR) & Phenylpropanoids & 0.29 & 3.37 \\
Ellagic acid (ELL) & Hydroxylated Biphenyls & 3.05 & 1.05 \\
Ferulic acid (FER) & Cinnamic Acids & 1.45 & 1.42 \\
Isoeugenol (ISO) & Phenylpropanoids & 0.72 & 2.52 \\
Propyl gallate (PGA) & Benzoic Acids & 3.32 & 1.51 \\
Vanillic acid (VAN) & Benzoic Acids & 0.76 & 1.24 \\
\hline
\end{tabular}

a TEAC, Trolox equivalent antioxidant capacity; ${ }^{\mathrm{b}} \log \mathrm{P}=$ lipophilicity estimated by theoretical calculations.

\subsection{In Vitro Activity}

To evaluate the compounds' activity, MYRO liquid medium with a $\mathrm{pH}$ of 6.5 [31] was prepared and autoclaved. The supplementation of the compounds was carried out as previously reported [25,32], with minor modifications. Briefly, the amount of $\beta$-CD that was necessary to obtain a final concentration of $3 \mathrm{mM}$ was dissolved under stirring for $1 \mathrm{~h}$ in degassed MYRO medium. Next, single phenolic compounds were separately added to the $\beta$-CD-MYRO solution to obtain final concentrations of $1 \mathrm{mM}$ each. Each mixture was agitated at $250 \mathrm{rpm}$ for $6 \mathrm{~h}$ at $25^{\circ} \mathrm{C}$ to promote the reversible inclusion of compounds in the $\beta-C D$ cavity and aliquoted in sterile flasks $(50 \mathrm{~mL})$. The flasks were supplemented with only water or $3.0 \mathrm{mM} \beta-\mathrm{CD}$ (without the tested compounds) to be used as controls. Conidial suspensions ( $10^{5}$ conidia per flask) of $100 \mu \mathrm{L}$ of $\mathrm{FvH}$ and $\mathrm{FvL}$ were inoculated, and the cultures were grown at $25^{\circ} \mathrm{C}$ in the dark for 10 days. On the basis of the results achieved at $1.0 \mathrm{mM}$, the most inhibitory compounds (ELL and ISO) were further investigated to identify lower concentrations ( 0.5 and $0.25 \mathrm{mM}$ ) that were able to decrease the FB content while preserving fungal growth. As a consequence of the decrease in the antioxidant dosage, the $\beta$-CD was also changed by reducing its concentration ( 1.5 and $0.75 \mathrm{mM})$, thus maintaining a molarity ratio between the $\beta-C D$ and phenols of 3:1. 


\subsection{Mycelial Growth Estimation and Fumonisin Quantification}

Ten-day-old fungal biomasses were separated from the liquid medium, rinsed thoroughly with tap water, collected on filter paper, and then oven-dried (DRY-Line 112 Prime, VWR Int. Ltd., Leicestershire, England) to obtain the dry weight $\left(105^{\circ} \mathrm{C}\right.$ for $\left.24 \mathrm{~h}\right)$. Because phenolic compounds can influence fungal growth and the secondary metabolism-and can even interact with the $\mathrm{pH}$ value - treated and untreated cultures were monitored at $0,1,3,5,7$, and 10 days after inoculation for their $\mathrm{pH}$. Liquid broths were harvested and stored at $-20^{\circ} \mathrm{C}$ for $\mathrm{FB}$ analysis. The FB accumulation was analyzed with a lateral flow test (Fumo-V strip, VICAM, Milford, MA, USA) with small modifications to the manufacturer's instructions. Briefly, $5 \mathrm{~mL}$ of culture broth separated from the mycelia was mixed with $20 \mathrm{~mL}$ of extraction buffer and vortexed for $2 \mathrm{~min}$. An aliquot of each extracted solution $(100 \mu \mathrm{L})$ was added to an immunostrip and quantified using a Vertu ${ }^{\circledR}$ lateral flow reader (VICAM, Milford, MA, USA). The limit of detection certified by the manufacturer for this kit was equal to $0.2 \mathrm{ppm}$. Due to the limitations of ELISA-based methods, the validation of the results was performed with FB-certified samples (LC-MS determination; NEOTRON spa, Modena, Italy).

\subsection{In Vivo Activity in Maize Kernels}

Based on the in vitro trials, four effective compounds (CAR, ELL, ISO, and PGA) were investigated for their efficacy in FB-free living maize kernels $(<100 \mathrm{mg} / \mathrm{kg})$. FER treatment, which was not effective in in vitro cultures at $1.0 \mathrm{mM}$ concentration, was included to verify whether this lack of efficacy was maintained in a different matrix. To prevent mycotoxin production by endophytic $F$. verticillioides, the experiments were conducted on externally and internally sterilized kernels [33]. For the in vivo treatments, the phenolic compounds were used at 1.0 and $3.0 \mathrm{mM}$ and complexed with 3.0 or $9.0 \mathrm{mM}$ of $\beta-\mathrm{CD}$, respectively, to maintain the proportions with the $\beta-C D$ used. Fifty grams of kernels were aseptically added to flasks containing $100 \mathrm{~mL}$ of compound solution and agitated for $3 \mathrm{~h}$ at $100 \mathrm{rpm}$ at $25^{\circ} \mathrm{C}$. The kernels were collected by discarding the solutions, and 20 seeds per plate were placed in $90 \mathrm{~mm}$ plates, inoculated with $100 \mu \mathrm{L}$ of spore suspension $\left(10^{6}\right.$ spores $\left./ \mathrm{mL}\right)$, and incubated at $25^{\circ} \mathrm{C}$ for 10 days without shaking. The kernels were harvested, oven-dried $\left(\sim 40{ }^{\circ} \mathrm{C}\right.$ for $\left.24 \mathrm{~h}\right)$, and milled to flour for FB analysis with the lateral flow test according to the manufacturer's instructions.

\subsection{Fum Gene Expression Analysis upon Phenolic Compound Treatment at $1.0 \mathrm{mM}$}

The fungal strains were treated with a set of phenolic compounds (CAR, ELL, FER, ISO, and PGA) as previously described, and were then grown for 7 days. FER was included to evaluate the effect of this compound at the transcription level; in vitro, it showed an almost opposite effect on $\mathrm{FvH}$ and $\mathrm{Fv} \mathrm{L}$. Further, with an under-dosed test, the gene expression was monitored for the ELL treatment with $0.25 \mathrm{mM}$, and the $\beta$-CD was changed by reducing its concentration to $0.75 \mathrm{mM}$. Fungal mycelia were harvested, rinsed thoroughly, immediately frozen in liquid nitrogen, and stored at $-80^{\circ} \mathrm{C}$ until RNA extraction. RNA was extracted using TRIzol reagent (Invitrogen, Carlsbad, CA, USA) and an RNA aliquot ( $1 \mu \mathrm{g})$ was treated with DNAse (PerfeCTa ${ }^{\circledR}$ DNase I, Quanta BioSciences, Gaithersburg, MD, USA) and reverse transcribed into cDNA using M-MLV reverse transcriptase and $25 \mu \mathrm{mol} / \mathrm{L}$ random primers according to the manufacturer's instructions (Invitrogen, Carlsbad, CA, USA). The gene expression of the set of biosynthetic genes (fum1, fum19, and fum21) involved in FB synthesis was analyzed using quantitative real-time PCR (qRT-PCR). One-tenth of the cDNA was used to optimize the PCR amplification and primer efficiency. qRT-PCR was performed using a StepOnePlus ${ }^{\mathrm{TM}}$ Real-Time PCR System (Applied Biosystems, Foster City, CA, USA). A total of $1 \mu \mathrm{L}$ of a cDNA dilution (corresponding to $25 \mathrm{ng}$ of total RNA) was amplified in $25 \mu \mathrm{L}$ of a reaction mixture containing Power SYBR green PCR master mix (Applied Biosystem, Foster City, CA, USA) and $200 \mu \mathrm{M}$ of each primer (tub2, fum1, and fum19) [34] and fum 21 [35], as shown Supplementary Materials Table S1. The amplification conditions consisted of 45 cycles as follows: $95{ }^{\circ} \mathrm{C}$ for $15 \mathrm{~s}$, annealing for $30 \mathrm{~s}$ at $58{ }^{\circ} \mathrm{C}$, 
and extension at $72{ }^{\circ} \mathrm{C}$ for $35 \mathrm{~s}$, followed by a final extension step of $4 \mathrm{~min}$ at $72{ }^{\circ} \mathrm{C}$. All of the reactions were performed with three technical replicates. $\beta$-tubulin was used as a reference gene to normalize the quantitative expression data. The relative expression of the qRT-PCR products was determined according to the method of Pfaffl [36] with the Q-Gene software [37]. Due to the normalization of the data, the figures reported the fold change calculated with respect to the same target in the untreated control. The gene expression for the untreated control was always set to 1.0 .

\subsection{Statistical Analysis}

Data were obtained through three independent experiments to determine the effects on fungal growth and FB accumulation, as well as two independent experiments for the effects on gene expression. Each treatment was performed with four replicates. If required, the results of the different experiments were analyzed after normalization against their respective untreated controls. A comparison of the fungal growth, FB content, and gene expression profiles of both strains was performed with the Kruskal-Wallis test (nonparametric rank comparison) followed by Dunn's test (nonparametric multiple comparisons). All of the calculations that included unmeasurable values $(<\mathrm{LOD}$, defined by the manufacturer as $\leq 200 \mu \mathrm{g} / \mathrm{kg}$ ) were conventionally considered contaminated by the half of the LOD value equal to $100 \mu \mathrm{g} / \mathrm{kg}$. The correlations between the gene expression levels and FB production as a consequence of the treatments were analyzed with Spearman's rank correlation. Analyses were performed with the XIStat 2016 software package (Addinsoft, NY, USA).

\section{Results}

\subsection{In Vitro Effect of Phenolic Compounds on FvH Growth and Fumonisin Production}

The compounds tested at $1.0 \mathrm{mM}$ exhibited different levels of inhibition of fungal growth and FB production by FvH (Table 2). ISO was the most effective inhibitor of fungal growth, leading to a relative decrease (RD) of almost $81.2 \%$, followed by ELL (46.9\% RD) and FER (27.8\% RD). Concerning FB accumulation, the ISO and ELL treatments inhibited FB production below the limit of detection (LOD), while the other three compounds (PGA, VAN, and CAR) ranged from $40.3 \%$ to $31.8 \%$. Because the inhibitory effect against the strain with the high FB production level was considered more valuable than that against the low-producing strain, these five phenolic compounds were selected to assess their effects on mycotoxin synthesis at the gene expression level. By monitoring the $\mathrm{pH}$ in the treated cultures (Supplementary Materials Table S2), the values observed after the treatments were very similar to those of the control, with small or localized deviations (CAF 0-5 dpi; CAR 3-10 dpi). The only compound that was able to consistently modify the $\mathrm{pH}$ values was ISO, which showed, starting at $1 \mathrm{dpi}, \mathrm{pH}$ values higher $(+0.3 \log \mathrm{pH}$ unit) than the $\mathrm{pH}$ observed in the untreated control.

\subsection{In Vitro Effect of Phenolic Compounds on FvL Growth and Fumonisin Production}

The response of $F v \mathrm{~L}$ to the tested compounds $(1.0 \mathrm{mM})$ corresponded to a generalized biomass decrease that ranged from $14 \%$ to $55 \%$, and only the CAF, PGA, and VAN treatments did not affect growth (Table 2). As occurred for $F v H$, the ELL and ISO treatments produced the highest growth reductions (54.5\% and 38.1\% RD, respectively), followed by APO (36.7\% RD), FER (20.5\% RD), and CAR (17.5\% RD). Concerning FB accumulation, six out of the eight treatments decreased mycotoxin content, with the largest reductions induced by ELL (97.2\% RD), APO (86.5\% RD), and FER (70.1\% RD). Differently from FvH, the non-complexed $\beta$-CD reduced both mycelial growth and FB accumulation by $14.0 \%$ and $57.9 \%$, respectively, when compared to the untreated control. An additional experiment was carried out to verify if the non-complexed $\beta-C D$ was able to sequester FBs in a liquid medium and contaminated maize flour. The results showed the inability of this adjutant to remove FBs from these substrates (data not shown). Similarly to the observations for $\mathrm{FvH}$, the $\mathrm{pH}$ values observed after the treatments were very similar to those of the controls 
(Supplementary Materials Table S3), with small or localized deviations (CAF 0-5 dpi; CAR 3-10 dpi). In this case, the ISO treatment also modified the $\mathrm{pH}$ over a time course of 3 to 7 dpi by increasing the values of the $+0.3 \log \mathrm{pH}$ units with respect to untreated control.

Table 2. In vitro effect of phenolic compounds $(1.0 \mathrm{mM})$ on fungal growth and fumonisin production.

\begin{tabular}{|c|c|c|c|c|}
\hline$F v \mathbf{H}$ & $\begin{array}{l}\text { Dry Fungal Biomass } \\
\quad(\text { rel. Yield } \pm \text { SE) }\end{array}$ & $\begin{array}{l}\text { Effect on } \\
\text { Biomass }+\end{array}$ & $\begin{array}{c}\text { FBs Content } \\
\text { (rel. Yield } \pm \text { SE) }\end{array}$ & $\begin{array}{l}\text { Effect on } \\
\text { FBs } t\end{array}$ \\
\hline Control & $100^{a b}$ & - & $100 \mathrm{ab}$ & \\
\hline$\beta-C D$ & $99.8 \pm 1.2^{\mathrm{ab}}$ & - & $123.5 \pm 3.8^{a}$ & - \\
\hline $\mathrm{APO}$ & $80.3 \pm 1.1^{a b c}$ & - & $76.6 \pm 0.9 \mathrm{bc}$ & - \\
\hline CAF & $94.1 \pm 1.2^{\mathrm{ab}}$ & - & $90.0 \pm 5.0^{b c}$ & - \\
\hline CAR & $93.6 \pm 4.2^{a b c}$ & - & $68.2 \pm 2.2^{c}$ & $-31.8 \%$ \\
\hline ELL & $53.1 \pm 3.4^{\mathrm{cd}}$ & $-46.9 \%$ & n.a. ${ }^{d}$ & $-99.2 \%$ \\
\hline FER & $72.2 \pm 2.1^{c}$ & $-27.8 \%$ & $136.1 \pm 3.9^{a b}$ & - \\
\hline ISO & $18.8 \pm 0.7^{\mathrm{d}}$ & $-81.2 \%$ & n.a. ${ }^{d}$ & $-99.2 \%$ \\
\hline PGA & $106.8 \pm 8.0^{\mathrm{a}}$ & - & $59.7 \pm 4.8^{c}$ & $-40.3 \%$ \\
\hline VAN & $103.4 \pm 6.1^{\mathrm{a}}$ & - & $70.0 \pm 0.5^{\mathrm{c}}$ & $-30.0 \%$ \\
\hline$F v \mathbf{L}$ & $\begin{array}{l}\text { Dry Fungal Biomass } \\
\quad \text { (rel. Yield } \pm \text { SE) }\end{array}$ & $\begin{array}{l}\text { Effect on } \\
\text { Biomass }+\end{array}$ & $\begin{array}{c}\text { FBs Content } \\
\text { (rel. Yield } \pm S E)\end{array}$ & $\begin{array}{l}\text { Effect on } \\
\text { FBs }+\end{array}$ \\
\hline Control & $100^{\mathrm{a}}$ & - & $100.0^{\mathrm{a}}$ & \\
\hline$\beta-C D$ & $86.0 \pm 3.8^{b}$ & $-14.0 \%$ & $42.1 \pm 0.6^{\mathrm{bc}}$ & $-57.9 \%$ \\
\hline $\mathrm{APO}$ & $63.3 \pm 0.9^{\mathrm{cd}}$ & $-36.7 \%$ & $13.5 \pm 0.8^{\mathrm{de}}$ & $-86.5 \%$ \\
\hline CAF & $93.0 \pm 1.7^{\mathrm{ab}}$ & - & $79.4 \pm 1.5^{\mathrm{ab}}$ & - \\
\hline CAR & $82.5 \pm 2.2^{b c}$ & $-17.5 \%$ & $41.5 \pm 0.1^{\mathrm{de}}$ & $-58.5 \%$ \\
\hline ELL & $45.5 \pm 4.1^{\mathrm{d}}$ & $-54.5 \%$ & n.a ${ }^{\mathrm{e}}$ & $-97.2 \%$ \\
\hline FER & $79.5 \pm 3.9^{c}$ & $-20.5 \%$ & $21.9 \pm 0.8^{\mathrm{de}}$ & $-78.1 \%$ \\
\hline ISO & $61.9 \pm 2.1 \mathrm{~cd}$ & $-38.1 \%$ & $49.1 \pm 0.4^{\mathrm{cd}}$ & $-50.9 \%$ \\
\hline PGA & $115.3 \pm 4.8^{a}$ & - & $46.2 \pm 0.8^{\mathrm{cd}}$ & $-53.8 \%$ \\
\hline VAN & $95.5 \pm 0.5^{a b}$ & - & $78.6 \pm 0.8^{a b}$ & - \\
\hline
\end{tabular}

Values were expressed as percentage relative to the level observed in the control culture for FvH (biomass: $153.0 \mathrm{mg}$; FBs: $12,950 \mu \mathrm{g} / \mathrm{kg}$ ) and FvL (biomass: $143.6 \mathrm{mg}$; FBs: $3650 \mu \mathrm{g} / \mathrm{kg}$ ). FB values were normalized on fungal dry weight. Values with different letters in the rows are significantly different $(p<0.05)$. Statistical analyses were performed separately per strain. n.a. not applicable due to FBs content $<$ LOD. + Effect on biomass and FBs was calculated as a percentage change with respect to untreated control data only for the statistically different treatments.

\subsection{In Vitro Effects of Reduced ELL and ISO Dosages on FvH and FvL}

ELL and ISO treatments with a stronger inhibitory capacity were further investigated to identify lower concentrations $(0.5$ or $0.25 \mathrm{mM})$ that were able to reduce FB biosynthesis while preserving fungal growth (Table 3). The data obtained on FvH for the ELL treatment showed that, differently from the 1.0 and $0.5 \mathrm{mM}$ treatments, the biomass obtained after the $0.25 \mathrm{mM}$ treatment was not different from that of the control, while the FB content remained significantly lower (<LOD). Conversely, for FvL, the $0.25 \mathrm{mM}$ ELL treatment inhibited fungal growth by $53.8 \%$ compared to the $61.3 \%$ obtained with the $0.5 \mathrm{mM}$ treatment; as a result, the FB values were once more below the LOD. Concerning the ISO treatments, while the $0.25 \mathrm{mM}$ treatment had no significant effects on $\mathrm{FvH}$ growth, a significant concomitant increase in mycotoxin biosynthesis $(+109.9 \%)$ occurred. Concerning FvL, the biomass increased with the dosage treatments from $89.5 \%$ to $104.9 \%$, and a concomitant increase in FB content was measured at $0.5 \mathrm{mM}(+149.6 \%)$.

\subsection{In Vivo Effect of Phenolic Compounds on Growth and FB Production by FvH}

To better estimate the performance of these inhibitors under in vivo conditions, untreated maize kernels and maize kernels treated with the most effective phenolic compounds (1.0 and $3.0 \mathrm{mM}$ ) were inoculated with $\mathrm{FvH}$ (Table 4). The results obtained for each phenolic compound showed that the two concentrations were able to affect FB production in opposite ways. The treatment at $3.0 \mathrm{mM}$ partly matched with the data obtained in vitro at $1.0 \mathrm{mM}$, resulting in a significant decrease in FB level as a result of ELL (81.2\% RD) and 
ISO (76.9\% RD), as well as CAR (96.6\% RD) and PGA (68.6\% RD). On the other hand, in addition to a significant mycotoxin decrease with the $1.0 \mathrm{mM}$ treatments of ELL and CAR ( $56.5 \%$ and $51.4 \% \mathrm{RD}$, respectively), FER and ISO drastically induced FB accumulation by $265.7 \%$ to $487.8 \%$, respectively. A significant reduction in FB production was observed with a high concentration of the $\beta-C D$ treatment $(9.0 \mathrm{mM})$, showing that this compound-in its free form-can have an effect on FB biosynthesis, depending on concentration.

Table 3. In vitro effect of ELL and ISO treatments $(1.0,0.5$, and $0.25 \mathrm{mM})$ on fungal growth and fumonisin production.

\begin{tabular}{|c|c|c|c|c|c|}
\hline \multicolumn{2}{|c|}{$F v \mathbf{H}$} & \multirow{2}{*}{$\begin{array}{c}\begin{array}{c}\text { Dry Fungal Biomass } \\
\text { (rel. Yield } \pm \text { SE) }\end{array} \\
100^{\mathrm{ab}}\end{array}$} & \multirow{2}{*}{$\begin{array}{c}\text { Effect on Biomass }+ \\
-\end{array}$} & \multirow{2}{*}{$\begin{array}{c}\begin{array}{c}\text { FBs Content } \\
\text { (rel. Yield } \pm \text { SE) }+\end{array} \\
100^{\mathrm{b}}\end{array}$} & \multirow{2}{*}{$\begin{array}{c}\text { Effect on } \\
\text { FBs }+ \\
-\end{array}$} \\
\hline Control & & & & & \\
\hline \multirow{6}{*}{$\mathrm{ISO}$} & $1.0 \mathrm{mM}$ & $48.4 \pm 5.4^{\mathrm{c}}$ & $-51.6 \%$ & n.a. ${ }^{\mathrm{d}}$ & $-99.5 \%$ \\
\hline & $0.5 \mathrm{mM}$ & $46.4 \pm 5.6^{\mathrm{c}}$ & $-53.6 \%$ & n.a. ${ }^{d}$ & $-99.5 \%$ \\
\hline & $0.25 \mathrm{mM}$ & $96.1 \pm 3.9^{b}$ & - & n.a. ${ }^{\mathrm{d}}$ & $-99.5 \%$ \\
\hline & $1.0 \mathrm{mM}$ & $19.7 \pm 0.9^{\mathrm{d}}$ & $-80.3 \%$ & n.a. ${ }^{\mathrm{d}}$ & $-99.5 \%$ \\
\hline & $0.5 \mathrm{mM}$ & $39.6 \pm 0.8^{c d}$ & $-60.4 \%$ & $55.9 \pm 4.9 \mathrm{bc}$ & - \\
\hline & $0.25 \mathrm{mM}$ & $120.9 \pm 2.9^{a}$ & - & $209.9 \pm 15.4^{a}$ & $+109.9 \%$ \\
\hline \multicolumn{2}{|c|}{$F v \mathbf{L}$} & $\begin{array}{l}\text { Dry Fungal Biomass } \\
\quad(\text { rel. Yield } \pm S E)\end{array}$ & Effect on Biomass † & $\begin{array}{c}\text { FBs Content } \\
\text { (rel. Yield } \pm S E) t\end{array}$ & $\begin{array}{l}\text { Effect on } \\
\text { FBs }+\end{array}$ \\
\hline \multirow[t]{4}{*}{ Control } & & $100^{\mathrm{b}}$ & & $100^{b}$ & - \\
\hline & $1.0 \mathrm{mM}$ & $39.9+0.6^{d}$ & $-60.1 \%$ & n.a. ${ }^{\mathrm{d}}$ & $-97.5 \%$ \\
\hline & $0.5 \mathrm{mM}$ & $38.7+2.3^{d}$ & $-61.3 \%$ & n.a. ${ }^{d}$ & $-97.5 \%$ \\
\hline & $0.25 \mathrm{mM}$ & $46.2+1.2^{\mathrm{cd}}$ & $-53.8 \%$ & n.a. ${ }^{\mathrm{d}}$ & $-97.5 \%$ \\
\hline \multirow{3}{*}{$\mathrm{ISO}$} & $1.0 \mathrm{mM}$ & $62.9+7.0^{b c}$ & - & $55.5+6.2^{\mathrm{cd}}$ & $-44.5 \%$ \\
\hline & $0.5 \mathrm{mM}$ & $204.9+16.6^{a}$ & $+104.9 \%$ & $249.6+10.1^{a}$ & $+149.6 \%$ \\
\hline & $0.25 \mathrm{mM}$ & $189.5+15.9^{a}$ & $+89.5 \%$ & $177.1+12.4^{a b}$ & - \\
\hline
\end{tabular}

Values were expressed as percentage relative to the level observed in the respective control for FvH (biomass: $168.2 \mathrm{mg}$; FBs: 16,720 $\mu \mathrm{g} / \mathrm{kg}$ ) and FvL (biomass: $145.4 \mathrm{mg}$; FBs: $3930 \mu \mathrm{g} / \mathrm{kg}$ ). Values with different letters in the rows are significantly different $(p<0.05)$. Statistical analyses were performed separately per strain. n.a. not applicable due to FBs content $<$ LOD. † Effect on biomass and FBs was calculated as a percentage change with respect to untreated control data only for the statistically different treatments.

Table 4. Effect of selected phenolic compounds on FBs production in maize kernels.

\begin{tabular}{|c|c|c|c|c|}
\hline & \multicolumn{2}{|c|}{$1.0 \mathrm{mM}$ Treatment } & \multicolumn{2}{|c|}{$3.0 \mathrm{mM}$ Treatment } \\
\hline & $\begin{array}{c}\text { FBs Content } \\
\text { (rel. Yield } \pm \text { SE) } \dagger\end{array}$ & Effect on FBs $\dagger$ & $\begin{array}{c}\text { FBs Content } \\
(\text { rel. Yield } \pm \text { SE) } \dagger\end{array}$ & Effect on FBs + \\
\hline Control & $100^{c}$ & & $100^{\mathrm{a}}$ & \\
\hline$\beta-C D$ & $98.9 \pm 8.8^{\mathrm{cd}}$ & - & $34.3 \pm 1.3^{b c}$ & -65.7 \\
\hline CAR & $48.6 \pm 4.3^{\mathrm{d}}$ & -51.4 & $3.4 \pm 1.5^{\mathrm{d}}$ & $-96.6 \%$ \\
\hline ELL & $43.5 \pm 2.2^{\mathrm{d}}$ & -56.5 & $18.8 \pm 3.6^{\mathrm{cd}}$ & $-81.2 \%$ \\
\hline FER & $365.7 \pm 16.1^{\mathrm{ab}}$ & +265.7 & $72.5 \pm 6.9^{a b}$ & - \\
\hline ISO & $587.8 \pm 3.9^{\mathrm{a}}$ & +487.8 & $23.1 \pm 1.9^{b c d}$ & -76.9 \\
\hline PGA & $157.8 \pm 17.2^{b c}$ & - & $31.4 \pm 3.5^{b c}$ & -68.6 \\
\hline
\end{tabular}

Values were expressed as percentage relative to the level observed in the control culture for $\mathrm{FvH}$ on sterile kernels (FBs: $18,540 \mu \mathrm{g} / \mathrm{kg}$ ). Values with different letters in the rows are significantly different $(p<0.05)$. Statistical analyses were performed separately per treatment. + Effect on FBs was calculated as a percentage change with respect to untreated control data only for the statistically different treatments.

\subsection{Effect of Phenolic Compounds on fum1 Expression}

The gene expression analysis of fum 1 revealed an intraspecific variation between the two fungal isolates: the fumonisin high- and low-producing strains. Concerning $\mathrm{FvH}$ (Figure $2 \mathrm{a})$, the most effective compounds $(1.0 \mathrm{mM})$ in reducing toxin content were ISO and ELL, which caused an almost complete down-regulation of fum 1 expression, followed by CAR, which had a 0.61 -fold change (f.c.) compared to the untreated control. FER, which did not have any significant effects on in vitro FB production, did not influence the transcription level of fum1. For FvL (Figure 2b), ELL, the most effective phenolic compound, 
downregulated fum 1 expression at 0.03 f.c., followed by FER ( 0.11 f.c.). Conversely, a strong up-regulation was induced by the ISO (9.48 f.c.) and PGA (5.12 f.c.) treatments, despite the few FBs that were detected. The CAR treatment, which was effective in FB reduction, resulted in a fum 1 expression level that was not different from that of the control. No significant difference in fum 1 expression was observed with $\beta-C D$ or the control. The statistical analysis revealed that the regulation of fum 1 expression by the tested compounds for $F v \mathrm{H}$ (rho $0.700 p<0.0001$ ) and $F v \mathrm{~L}$ (rho $0.455 p=0.001$ ) correlated with FB production.

a

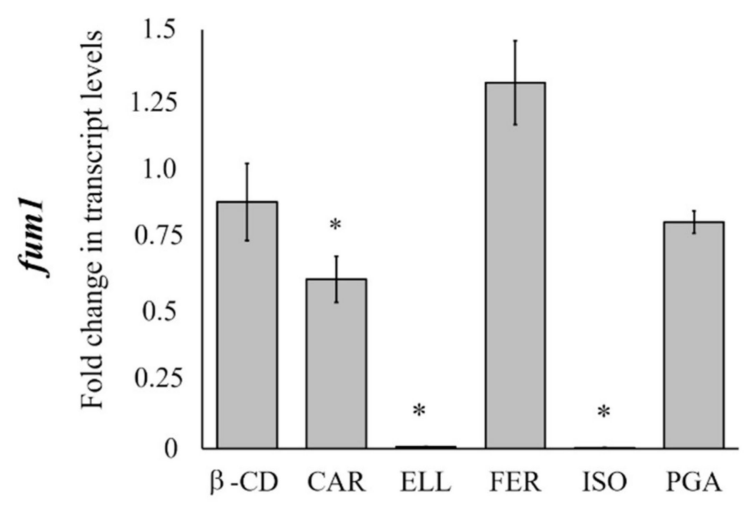

c

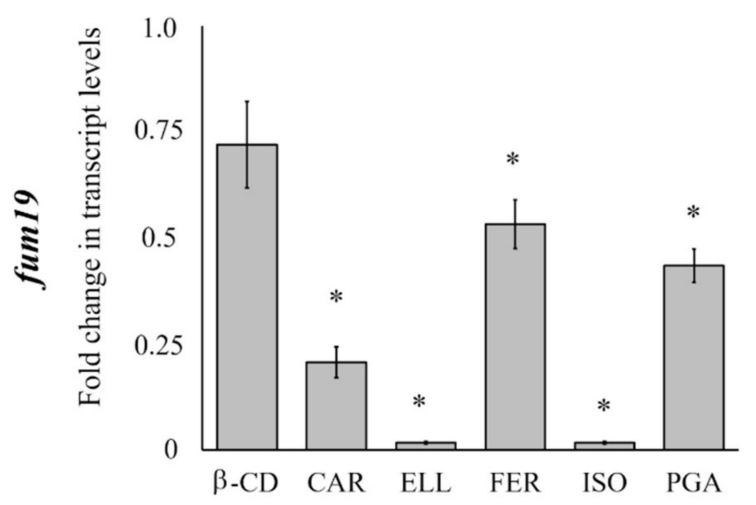

e

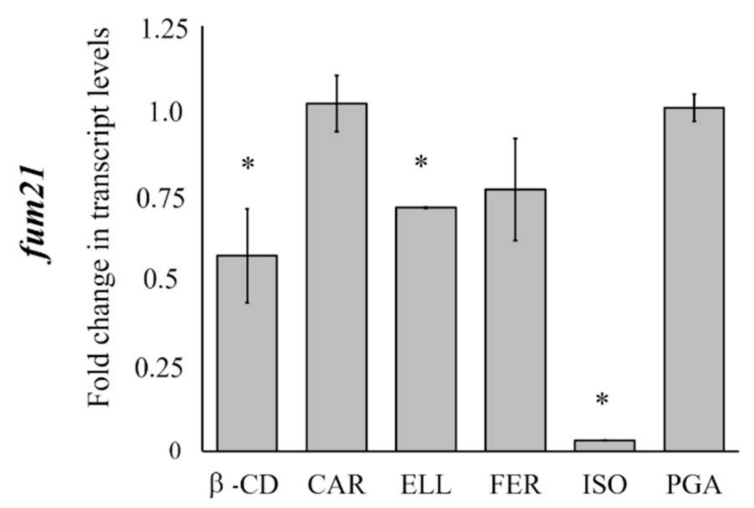

b

$F v \mathbf{L}$
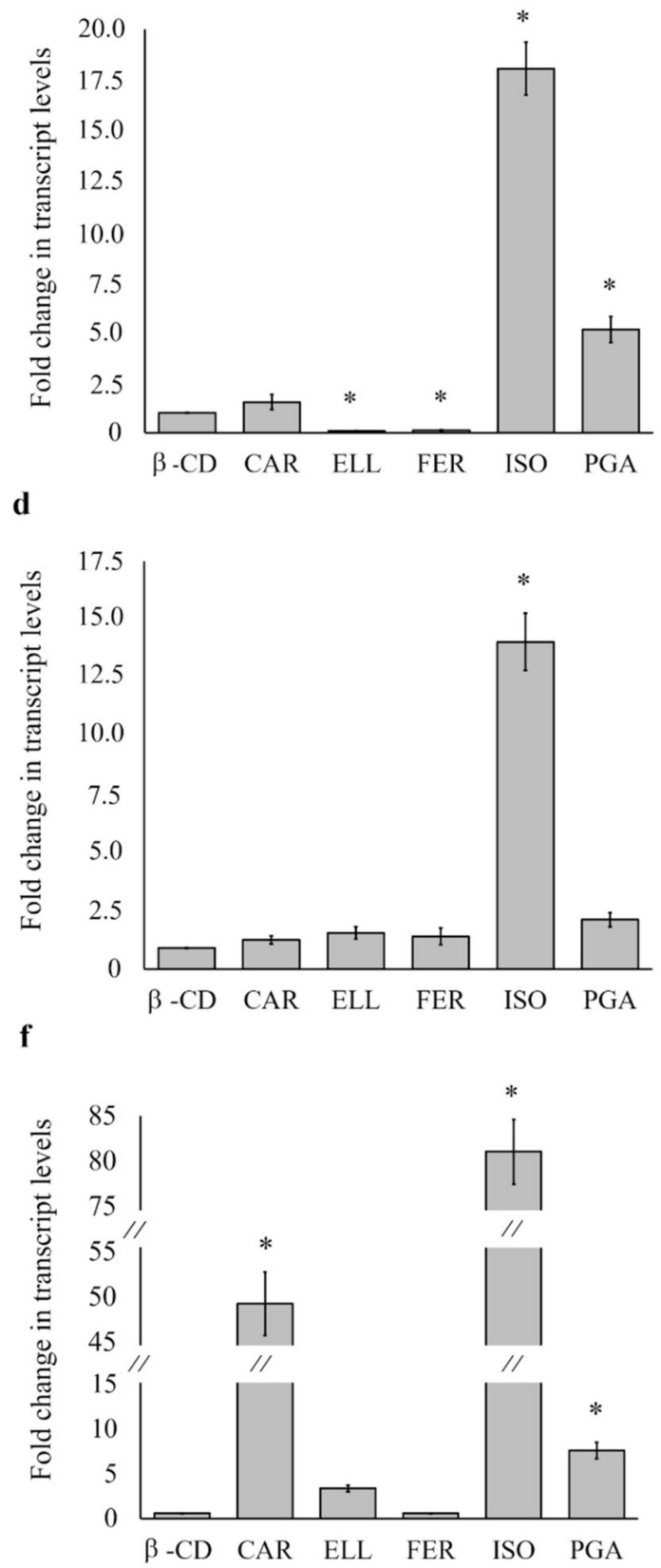

Figure 2. Fold changes on fum gene expression observed on FvH (figures on the left; a: fum1; c: fum19; e: fum21) and FvL (figures on the right; b: fum1; d: fum19; f: fum21) in response to selected $1.0 \mathrm{mM}$ phenolic compound treatments with respect to values observed on untreated cultures. Due to data normalization, the expression level calculated for untreated control was set to 1.0. Bars represent the average value \pm standard error. Bars with asterisks $\left(^{*}\right)$ are significantly different to untreated control according to Kruskal-Wallis and Dunn's test $(p<0.05)$. 


\subsection{Effect of Phenolic Compounds on fum19 Expression}

The analysis of fum19 expression with $\mathrm{FvH}$ (Figure 2c) showed that it was downregulated by all of the tested compounds $(1.0 \mathrm{mM})$ in the following order: ELL and ISO (0.02 f.c., both), CAR ( 0.21 f.c.), and PGA (0.43 f.c.). Moreover, although the FER treatment did not result in a significant decrease in FB production, a down-regulation of gene expression ( 0.53 f.c.) was observed. Conversely, a different behavior was shown in the fum19 gene expression in FvL (Figure 2d); the decrease in FB production was not linked to a down-regulation of the gene expression level, and ISO led to a sharp up-regulation of the transcription levels (14.04 f.c.). No significant difference was observed in the gene expression of $\beta-C D$ and the control. The data obtained clearly showed that the fum 19 expression after the treatments was correlated with the FB content for $\mathrm{FvH}$ (rho 0.649 $p<0.0001$ ), but this effect was lacking for strain L (rho $0.001 p=0.986$ ).

\subsection{Effect of Phenolic Compounds on fum21 Expression}

Similarly to that of fum 1 and fum 19 , the gene expression of fum 21 was differentially regulated between the strains with the $1.0 \mathrm{mM}$ treatments. Fum21 in strain $\mathrm{FvH}$ (Figure 2e) was down-regulated in response to the treatments with ISO ( 0.03 f.c.) and ELL ( 0.71 f.c.). The CAR and PGA treatments did not show considerable differences in gene expression, despite the fact that both compounds reduced the FB production. No effect of FER on fum 21 expression was observed. Concerning the FvL strain (Figure 2f), with the exception of FER and $\beta-C D$, which down-regulated gene expression ( 0.60 f.c.; both), the other compounds strongly induced gene expression. In particular, ISO, CAR, and PGA increased fum 21 transcription by 79.0, 48.9, and 6.6 times, respectively. These data showed that the treatments with phenolic compounds acted on fum 21 expression in an opposite way with respect to the FB content; therefore, no correlation was observed for $F v \mathrm{H}$ (rho $0.037 p=0.400$ ) and FvL (rho $0.061 p=0.277$ ).

\subsection{Effect of Under-Dosed ELL Treatment on Fum Gene Expression}

Considering the efficacy of the tested phenolic compounds at different concentrations with respect to mycelial growth and FB production, ELL was further investigated with a gene expression analysis at the concentration of $0.25 \mathrm{mM}$. For both strains, the $0.25 \mathrm{mM}$ ELL treatment decreased the gene expression (Figure 3). With respect to $\mathrm{FvH}$, the treatment significantly reduced the expression of fum1, fum 19 , and fum 21 by $0.39,0.30$, and 0.45 times, respectively, thus confirming the data obtained after the ELL treatment at $1.0 \mathrm{mM}$. Moreover, the decrease in fum 21 expression with FvL was similar to that which occurred for $\mathrm{FvH}(0.37$ f.c.); on the other hand, the expression of fum 1 and fum 19 was more inhibited by the $0.25 \mathrm{mM}$ treatment ( 0.02 and 0.01 f.c., respectively). Furthermore, the behavior of fum19 in FvL was different from that obtained with the same treatment at $1.0 \mathrm{mM}$ where the transcription did not appear to be different from that of the control. Similarly, the fum 21 expression in both strains with $0.25 \mathrm{mM}$ of ELL displayed a decrease that was different from that of the standard dosage. 
a

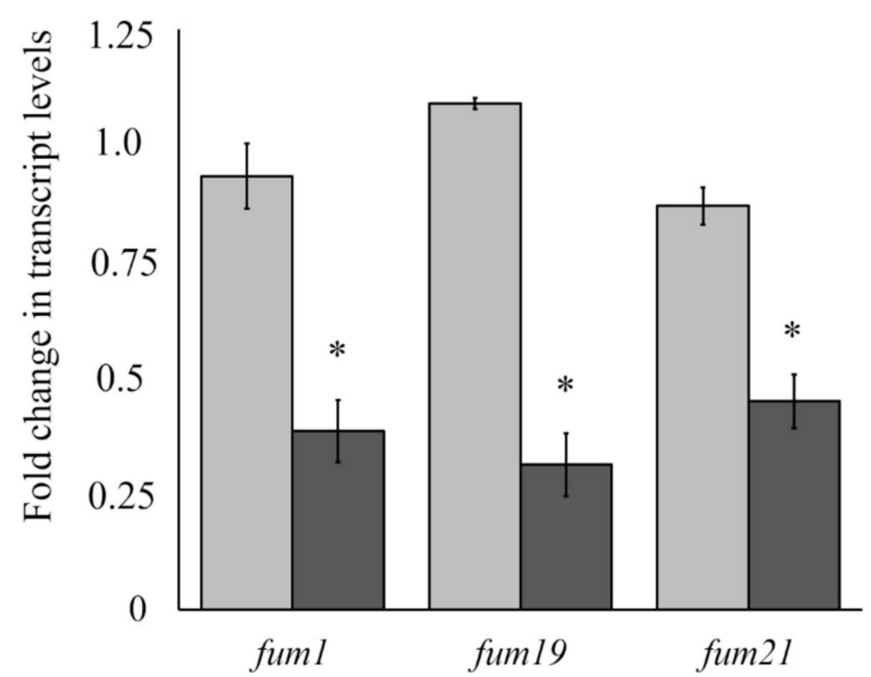

b

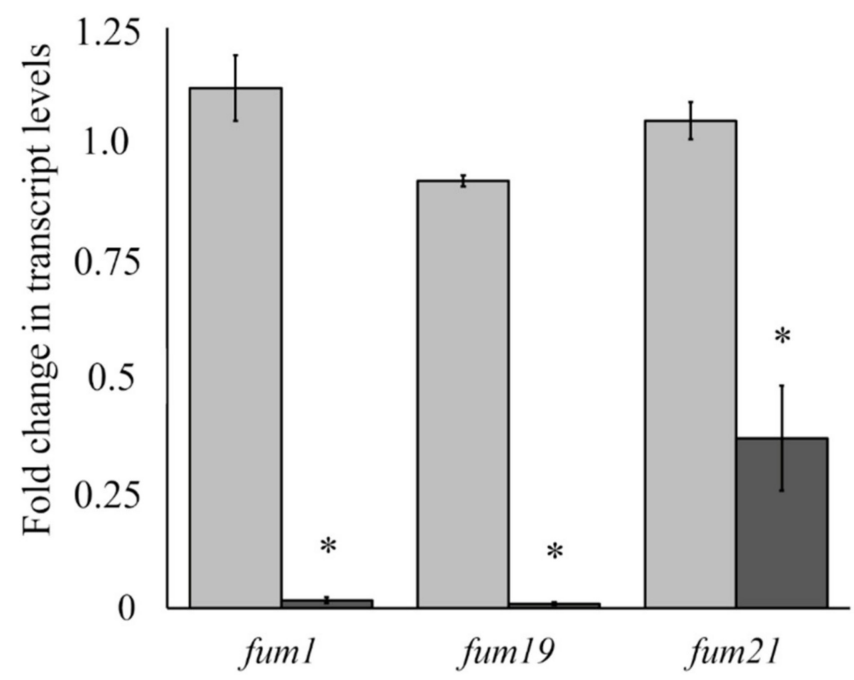

Figure 3. Effect of ELL $0.25 \mathrm{mM}$ treatment on gene expression. Fold change in fum1, fum19, and fum 21 gene expression by $\mathrm{FvH}(\mathbf{a})$ and $\mathrm{FvL}(\mathbf{b})$ in response to $\beta-\mathrm{CD}$ control $(0.75 \mathrm{mM}$; light gray bars) and ELL treatments $(0.25 \mathrm{mM}$; dark gray bars). Due to data normalization, the expression level calculated for untreated control was set to 1.0. The fold change was calculated according to the expression values observed for each gene on untreated cultures. Bars represent the average value \pm standard error. Bars with asterisks $\left({ }^{*}\right)$ are significantly different to untreated control according to Kruskal-Wallis and Dunn's test $(p<0.05)$.

\section{Discussion and Conclusions}

To investigate the in vitro effects of naturally occurring phenols on the growth of F. verticillioides and FB production, eight phenolic compounds were tested in two strains that differed in their abilities to produce FBs. The sensitivities of $\mathrm{FvH}$ and $\mathrm{FvL}$ to these compounds at the selected concentrations were heterogeneous. Concerning their effect on the fungal growth of the $\mathrm{FvH}$ strain, the majority of compounds produced no significant difference with respect to the untreated cultures at $1.0 \mathrm{mM}$, except for ISO, ELL, and FER. In contrast, the response of the FvL strain to the phenols exhibited a generalized biomass decrease, and only CAF, PGA, and VAN were ineffective. With respect to FB production, five (CAR, ELL, ISO, PGA, and VAN) out of the eight treatments decreased the FB content produced by the $\mathrm{FvH}$ strain, with decreases ranging from 30 to 99.2\%; six (APO, CAR, ELL, FER, ISO, and PGA) out of the eight treatments decreased the FB content produced by the FvL strain, with values ranging from 50.9\% to $97.2 \%$. Considering the data on fungal growth and FB production, some compounds were effective against a single strain or both strains, and the small changes in $\mathrm{pH}$ due to the supplementation of the phenols could not explain the observed variability. A specific phenolic compound could, therefore, modulate fungal growth and mycotoxin production differently according to the strain. The variations in the effects among the phenolic compounds and the different Fusarium isolates could likely be attributed to physical and chemical properties, such as the lipophilicity and antioxidant activity [38], to both fungal genus and strain features [15,39-41], or to the degradation of phenols into less effective molecules [42-44]. Our investigation focused on the identification of natural compounds that were able to inhibit mycotoxin production with a limited fungicidal effect. Despite the strong reduction in biomass at the concentration of $1.0 \mathrm{mM}$, ELL and ISO can be considered promising for controlling FBs with particular efficacy in a high-producer strain $(F v H)$. However, to reduce the fungicidal effect caused by ELL and ISO on the fungal growth at $1.0 \mathrm{mM}$, they were under-dosed at 0.5 and $0.25 \mathrm{mM}$. Concerning ELL, each investigated concentration inhibited FB production, and the in vitro fungal growth was restored by diminishing its concentration to $0.25 \mathrm{mM}$, resulting in a functional concentration for in vitro FB inhibition. The inhibitory effect on FB production 
after the $1.0 \mathrm{mM}$ ELL treatment was also observed in F. culmorum ISPaVe MCf21 [25]. However, another strain named FcUK99 induced an increase in trichothecene production of $59 \%$ at the same concentration [45]. On the contrary, the under-dosed ISO treatments $(0.5$ and $0.25 \mathrm{mM})$ promoted FB content in both strains-they maintained a fungicidal effect $(F v H)$ or increased the growth of the biomass $(F v \mathrm{~L})$, depending on strain. These behaviors are different from those observed in F. verticillioides MRC4316 [8], in which a high ISO concentration produced a strong growth inhibition, while the $1.0 \mathrm{mM}$ treatment did not alter the FB production [46]. Significant increases in biomass as a consequence of antioxidant treatments were already reported in F. graminearum and F. poae, where p-hydroxybenzoic acid, vanillic acid, quercetin, and rutin slightly stimulated mycelium growth [47]. Indeed, concerning the increased toxin content, it is not uncommon for a low phenolic concentration to be more inductive than a higher one; in fact, in F. culmorum, ISPaVe MCf21, a eugenol dimer at a concentration of $1.0 \mathrm{mM}$, promoted 3ADON biosynthesis by 2.24 times compared to the control, whereas a concentration of $0.5 \mathrm{mM}$ promoted toxins by 4.51 times [25]. Concerning the other compounds tested, some chemicals (APO, CAF, VAN, FER, CAR, and PGA) were less effective than expected. The effective reduction observed in the growth and mycotoxin content after APO treatment in FvL (36.7 and 86.5, respectively) was similar to the data reported for F. culmorum INRA 117 (44\% and 100\% decreases in biomass and 3-ADON, respectively) [45]; on the other hand, these effects strongly diminished for $\mathrm{FvH}$ (19.7\% and 23.4\%). Regarding the fungal growth and FB content in FvH and FvL after the CAF and VAN treatments, the results were quite low for both strains, confirming the previous reports for F. verticillioides $25 \mathrm{~N}$ and F. proliferatum $73 \mathrm{~N}$, where low or no efficacy was observed at the concentration of $500 \mu \mathrm{g} / \mathrm{g}$ in corn (equivalent to a $\sim 3 \mathrm{mM}$ solution) [40]. However, their use should be deeply investigated, because a consistent FB reduction by these compounds was reported in F. verticillioides MRC826 [48] and F. verticillioides 63 [44], suggesting a strong dependence by the strain. As a further compound, FER is one of the most investigated phenols for mycotoxin control due to its ability to interfere with deoxynivalenol production $[9,49]$. In our experiments, FER showed a small reduction in fungal growth for both strains (21.5-27.8\%), but the FB was decreased by $78.1 \%$ only in the low-producing strain $(F v \mathrm{~L})$, and this was not observed in the high-producing strain $(F v \mathrm{H})$. The data obtained from the FER treatments are complex and depend on the concentration; in F. verticillioides M7075 and F. proliferatum RC 2080, treatments at concentrations of 1-10 mM increased both the growth and FB content [50], with a trend for FB content similar to that observed in $\mathrm{FvH}$. These authors also stated that FER treatments at higher concentrations (20-25 mM) were effective in reducing fungal activity, and similar results were obtained by Nesci and colleagues [51] for Aspergillus section Flavi and its aflatoxin production. Concerning CAR and PGA, to our knowledge, few reports are available for these treatments for toxigenic fungi, and the present data provide evidence for a larger tolerance of both $F v \mathrm{H}$ and $F v \mathrm{~L}$ toward CAR. On the contrary, application of CAR at $1 \mathrm{mM}$ in F. verticillioides MRC 4316 decreased conidial germination ( $94.7 \%$ vitality reduction) in an investigation by Dambolena and colleagues [8]. Similarly, PGA, which showed a weaker effect on the strains that we investigated, caused decreases in biomass $(88.0 \%$ and $97.7 \%)$ and 3-ADON production in F. culmorum FcUK99 [45].

A set of five compounds (CAR, ELL, FER, ISO, and PGA) that were found to be the best FB inhibitors in our in vitro experiments was assayed in vivo in sterile kernels. The FB reduction in the kernels was evaluated at two concentrations (1.0 and $3.0 \mathrm{mM})$. At $1.0 \mathrm{mM}$, only CAR and ELL were effective as FB inhibitors, unlike the other phenols, which were ineffective or even had negative consequences. However, after treatments at $3 \mathrm{mM}$, the FB content was strongly reduced by CAR (96\%) and ELL (81\%). For the other compounds, the FB content appeared to be rather similar to that in the data obtained in vitro. Some authors have indicated that the efficacy of phenolic compounds could be related to their lipophilicity or antioxidant properties [16,52,53]; however, the balance of these two properties has been suggested as a key factor for mycotoxin control [25,54,55]. Instead, ELL and ISO molecules, which are characterized by intermediate chemical properties 
(ELL: TEAC 3.05, LogP 1.05; ISO: TEAC 0.72, LogP 2.52), strongly influenced the fungal biomass. As previously mentioned, one of the properties that determines absorption and translocation is lipophilicity, which is measured as LogP [28]. Because Yang and colleagues indicated 3.39 as the $\log \mathrm{P}$ value with the maximal tissue uptake in maize kernels [56], chemicals with a $\log P$ value that is far from this value should be taken up with lower efficiency, thus modulating the actual concentration of each compound in the kernel tissues. Interestingly, our treatments performed with CAR - which should cross the cell layers with the highest rate allowed by the kernel tissues-in maize $(\operatorname{LogP} 3.37)$ caused a significant FB reduction, which was observed at both 1.0 and $3.0 \mathrm{mM}$, with better results than those obtained in vitro. In contrast, when applied as a fumigant, the same treatment was found to be able to control $F$. verticillioides in experiments in vitro and in naturally infected kernel, but the same concentration failed to control the FB content [57]. The discrepancies obtained in these studies between the in vitro and in vivo conditions could likely be explained by the ready availability of the tested phenols in in vitro experiments, which, when applied to kernels, could be less effective due to a delayed or selective absorption through tissues. Further explanations could involve a possible degradation of the phenolic compounds by the metabolism of living seeds [58] or modifications of their chemical properties due to $\mathrm{pH}$, which can further modify the stability of these molecules [59]. As previously found, phenols with high antioxidant capacities can act by interfering with redox-sensitive cellular components [60]. Their high lipophilicity values can alter their ability to interact with the polar groups of membranes [54]. For these reasons, the inhibition of fungal growth and FB content by these two compounds characterized by quite opposite antioxidant capacities and lipophilicity could likely be due to their different mechanisms of interference. Taken together, these results provide new insights into the efficacy of phenols as inhibitors of $\mathrm{FB}$ production, suggesting ELL and CAR as the most promising for their efficacy as inhibitors at lower doses in order to limit the negative antifungal properties. Moreover, under-dosing some compounds can increase mycotoxin production, as was found for the eugenol dimer, showing that some compounds should be carefully evaluated [25]

It should be noted that cyclodextrin was considered to be inert without detrimental interferences in fungal metabolism $[25,61]$. However, in the present study, $3 \mathrm{mM} \beta-C D$ reduced the in vitro $\mathrm{FB}$ content in the $\mathrm{FvL}$ strain. On the other hand, when its concentration was increased to $9.0 \mathrm{mM}$, such as in the in vivo experiment, $\beta$-CD was also effective against the high-producing strain $(F v H)$. Although the results of the in vivo and in vitro experiments did not fully overlap, this behavior could suggest a dose- and strain-dependent response. However, no clear activity can be proposed for this adjuvant; indeed, the FER treatments were ineffective in spite of the presence of $3.0 \mathrm{mM} \beta-\mathrm{CD}$; therefore, no direct effects were observed for the FER- $\beta$-CD complex. This aspect could indicate that, when in free form, cyclodextrin might interact with some metabolites, sequester them, or create less favorable environments for FB biosynthesis.

The effect of phenolic compound treatments in fungi can include the impairment of cellular ionic homeostasis and redox potential, the quenching of free radicals, and the inhibition of redox-sensitive enzymes $[17,62,63]$. Because most of these aspects are also involved in mycotoxin initialization and production, the expression of a set of representative fum genes involved in the FB biosynthetic pathway was analyzed after the treatments. Similarly to the mycotoxin content, where a large variability was observed between strains with respect to FB production, the gene expression also demonstrated a similar variability. Interestingly, ISO was the only compound that coherently decreased or increased the expression of the three investigated genes-fum1, fum 19, and fum 21 -in $\mathrm{FvH}$ and $F v \mathrm{~L}$, respectively. Fum 1 encodes for a polyketide synthase-the first step required for the biosynthesis of FBs [64] —and its inhibition or knock-out leads to the stopping of FB synthesis $[65,66]$. Concerning the gene expression of fum 1 in $\mathrm{FvH}$, the levels were strongly down-regulated by ISO, ELL, and CAR, and this correlated the low FB accumulation in the in vitro culture. A negative effect on fum 1 gene expression and FB production was observed [67] after treatments with naturally occurring phenolic compounds extracted 
from Cuminum cyminum essential oil in a Fusarium verticillioides strain [68]. In contrast, the fum 1 expression in FvL was down-regulated in response to ELL and FER, while a strong up-regulation was observed after the ISO and PGA treatments. Although the fum genes in FvL were up-regulated during these specific interactions, the FB content accumulated at very low levels. Similar results linking small amounts of toxins to increased gene transcription were suggested for the TRI genes in F. graminearum $\mathrm{PH}-1$ treated with a low dosage $(0.25 \mathrm{mM})$ of thymol or thymol with magnolol [15]. Our data suggest that some compounds might not only regulate mycotoxin production at the transcription level $[43,69,70]$, but could also be effective at the post-transcription level, as suggested for trichodiene synthase (TRI5) in F. culmorum [45]. Indeed, as proposed by Pani and colleagues by working on a TRI5 model, phenolic compounds could interact with functional groups or amino acids that are putatively involved in enzymatic interactions by modifying or modulating its activity [45]. Another gene involved in FB biosynthesis is fum19, an ABC transporter that is involved in the extracellular export of fumonisins and is responsive to stress challenges [71-73]. Although several investigations of fum 19 gene $[34,74,75]$ showed that it is not essential for FB production and that its deletion displayed few effects on the synthesis of these toxins $[65,76]$, other experiments suggested a positive correlation with mycotoxin production $[77,78]$. In light of the present experiments, a positive correlation between fum19 expression and FB content was observed for the $\mathrm{FvH}$ strain, and the trend of fum 19 expression was similar to that observed for fum1. Similar conclusions could not be drawn for the FvL strain, in which, despite the decrease in mycotoxin accumulation, fum 19 expression appeared to be almost completely unaffected by the treatments, and the only matching treatment was ISO. By working with a fum19-deleted F. proliferatum strain, previous authors suggested that this gene likely exerts a negative regulatory effect on fum1 [76]; however, we could not evaluate it, because significant reductions in fum 19 expression did not correspond to increases in fum1.

As observed for the previously mentioned genes, fum 21 was also differentially expressed among the different treatments and strains. In the $F v \mathrm{H}$ strain, only the ISO treatment caused a strong down-regulation of fum 21 , and FB production was completely inhibited. Because fum 21 is a transcription factor that is required for FB production [79], its up-regulation in the FvL strain should have caused an enrichment in mycotoxin production; however, despite its up-regulation with the ISO and PGA treatments, FB accumulation was inhibited by these treatments. These findings suggested that phenolic compounds can affect FB accumulation by generally down-regulating fum gene expression; however, some treatments in the FB low-producing F. verticillioides were able to up-regulate fum gene expression without improving FB production. However, apart from the gene cluster for FB biosynthesis, additional genes, including, FCC1 [80], ZFR1 [81], FCK1 [82], AREA [83], and FvVE1 [84], are also involved in FB regulation. These genes might also be responsive to the phenolic compounds that modulate FB production. Interestingly, at $3.0 \mathrm{mM}$, non-complexed $\beta$-CD demonstrated a certain activity against FB biosynthesis by reducing fum 21 expression in $F v \mathrm{H}$, but to a limited extent.

The findings of the present work contribute to the knowledge of phenolic compounds as effective molecules for the containment of FBs. These compounds showed diverse efficacy with respect to fungal growth and FB accumulation in in vitro and in vivo experiments, and it was found that the effects of the compounds were also dependent on the strain. This aspect must be taken into consideration for future applications in the open field, as Fusarium populations are wide and heterogeneous. However, two out of the eight compounds- in particular CAR and ELL—were shown to reduce FB accumulation in F. verticillioides in vitro and in kernels. In conclusion, we identified some natural phenols that are able to significantly reduce FB accumulation; they seem to be promising molecules that can be evaluated as biopesticides under open-field conditions in order to control fumonisin occurrence in maize. As the next step, these phenolic compounds should be tested in maize plants from the silking to the dough stage, as these stages are particularly sensitive 
to F. verticillioides colonization. However, the number and dosage of the treatments need to be evaluated in the field along with agronomic practices.

Supplementary Materials: The following are available online at https://www.mdpi.com/article/10 .3390/agronomy11061060/s1. Table S1: List of primers used for FB-related gene expression analysis; Table S2: $\mathrm{pH}$ values measured in the high-FB producer strain treated flasks; Table S3: pH values measured in the low-FB producer strain treated flasks.

Author Contributions: Conceptualization, D.F. and A.R.; methodology, D.F. and S.B.; validation, D.F., S.B., and M.M.; formal analysis, D.F. and M.M.; investigation, D.F., S.B., and M.M.; resources, A.R.; data curation, D.F.; writing-original draft preparation, D.F. and S.B.; writing-review and editing, A.R..; funding acquisition, A.R. All authors have read and agreed to the published version of the manuscript.

Funding: This research was funded by Institutional Grants of University of Padova (DOR1671101/16).

Data Availability Statement: The authors declare that the data supporting the findings of this study are available within the paper and its supplementary information files. Raw data are available from the corresponding author upon reasonable request.

Acknowledgments: This research work has been developed as a result of Mobility Stay funded by the Erasmus+-KA1 Erasmus Mundus Joint Master Degrees Programme of the European Commission under the PLANT HEALTH Project.

Conflicts of Interest: We declare no conflict of interest.

\section{References}

1. Smith, G.W. Fumonisins. In Veterinary Toxicology; Elsevier: Amsterdam, The Netherlands, 2018; pp. $1003-1018$.

2. Claeys, L.; Romano, C.; De Ruyck, K.; Wilson, H.; Fervers, B.; Korenjak, M.; Zavadil, J.; Gunter, M.J.; De Saeger, S.; De Boevre, M. Mycotoxin exposure and human cancer risk: A systematic review of epidemiological studies. Compr. Rev. Food Sci. Food Saf. 2020, 19, 1449-1464. [CrossRef]

3. Ferrigo, D.; Raiola, A.; Causin, R. Fusarium toxins in cereals: Occurrence, legislation, factors promoting the appearance and their management. Molecules 2016, 21, 627. [CrossRef] [PubMed]

4. Van Rensburg, B.J.; Mc Laren, N.W.; Schoeman, A.; Flett, B.C. The effects of cultivar and prophylactic fungicide spray for leaf diseases on colonisation of maize ears by fumonisin producing Fusarium spp. and fumonisin synthesis in South Africa. Crop Prot. 2016, 79, 56-63. [CrossRef]

5. Becher, R.; Hettwer, U.; Karlovsky, P.; Deising, H.B.; Wirsel, S.G. Adaptation of Fusarium graminearum to tebuconazole yielded descendants diverging for levels of fitness, fungicide resistance, virulence, and mycotoxin production. Phytopathology 2010, 100, 444-453. [CrossRef] [PubMed]

6. Torres, A.M.; Ramirez, M.L.; Arroyo, M.; Chulze, S.N.; Magan, N. Potential use of antioxidants for control of growth and fumonisin production by Fusarium verticillioides and Fusarium proliferatum on whole maize grain. Int. J. Food Microbiol. 2003, 83, 319-324. [CrossRef]

7. Farnochi, M.C.; Torres, A.M.; Magan, N.; Chulze, S.N. Effect of antioxidants and competing mycoflora on Fusarium verticillioides and F. proliferatum populations and fumonisin production on maize grain. J. Stored Prod. Res. 2005, 41, 211-219. [CrossRef]

8. Dambolena, J.S.; López, A.G.; Meriles, J.M.; Rubinstein, H.R.; Zygadlo, J.A. Inhibitory effect of 10 natural phenolic compounds on Fusarium verticillioides. A structure-property-activity relationship study. Food Control 2012, 28, 163-170. [CrossRef]

9. Gauthier, L.; Atanasova-Penichon, V.; Chéreau, S.; Richard-Forget, F. Metabolomics to decipher the chemical defense of cereals against Fusarium graminearum and deoxynivalenol accumulation. Int. J. Mol. Sci. 2015, 16, 24839-24872. [CrossRef]

10. Bruneton, J. Pharmacognosy, Phytochemistry, Medicinal Plants; Lavoisier Publishing: Paris, France, 1995; ISBN 2-7430-0028-7.

11. Škerget, M.; Kotnik, P.; Hadolin, M.; Hraš, A.R.; Simonič, M.; Knez, Ž. Phenols, Proanthocyanidins, flavones and flavonols in some plant materials and their antioxidant activities. Food Chem. 2005, 89, 191-198. [CrossRef]

12. Sung, W.S.; Lee, D.G. Antifungal action of chlorogenic acid against pathogenic fungi, mediated by membrane disruption. Pure Appl. Chem. 2010, 82, 219-226. [CrossRef]

13. Rao, A.; Zhang, Y.; Muend, S.; Rao, R. Mechanism of antifungal activity of terpenoid phenols resembles calcium stress and inhibition of the TOR pathway. Antimicrob. Agents Chemother. 2010, 54, 5062-5069. [CrossRef]

14. Sanzani, S.M.; Schena, L.; Nigro, F.; De Girolamo, A.; Ippolito, A. Effect of quercetin and umbelliferone on the transcript level of Penicillium expansum genes involved in patulin biosynthesis. Eur. J. Plant Pathol. 2009, 125, 223-233. [CrossRef]

15. Oufensou, S.; Balmas, V.; Azara, E.; Fabbri, D.; Dettori, M.A.; Schüller, C.; Zehetbauer, F.; Strauss, J.; Delogu, G.; Migheli, Q. Naturally occurring phenols modulate vegetative growth and deoxynivalenol biosynthesis in Fusarium graminearum. ACS Omega 2020, 5, 29407-29415. [CrossRef] 
16. Ponts, N.; Pinson-Gadais, L.; Boutigny, A.-L.; Barreau, C.; Richard-Forget, F. Cinnamic-Derived acids significantly affect Fusarium graminearum growth and in vitro synthesis of type B trichothecenes. Phytopathology 2011, 101, 929-934. [CrossRef] [PubMed]

17. Atanasova-Penichon, V.; Barreau, C.; Richard-Forget, F. Antioxidant secondary metabolites in cereals: Potential involvement in resistance to Fusarium and mycotoxin accumulation. Front. Microbiol. 2016, 7, 566. [CrossRef] [PubMed]

18. Narasaiah, K.V.; Sashidhar, R.B.; Subramanyam, C. Biochemical analysis of oxidative stress in the production of aflatoxin and its precursor intermediates. Mycopathologia 2006, 162, 179. [CrossRef] [PubMed]

19. Reverberi, M.; Zjalic, S.; Ricelli, A.; Fabbri, A.A.; Fanelli, C. Oxidant/Antioxidant balance in Aspergillus parasiticus affects aflatoxin biosynthesis. Mycotoxin Res. 2006, 22, 39-47. [CrossRef] [PubMed]

20. Leslie, J.F.; Summerell, B.A. The Fusarium Laboratory Manual; John Wiley \& Sons: Hoboken, NJ, USA, 2008; ISBN 0-470-27646-0.

21. Mulè, G.; Susca, A.; Stea, G.; Moretti, A. A species-specific PCR assay based on the calmodulin partial gene for identification of Fusarium verticillioides, F. proliferatum and F. subglutinans. Eur. J. Plant Pathol. 2004, 110, 495-502. [CrossRef]

22. Tuite, J. Plant Pathological Methods: Fungi and Bacteria; Burgess Publishing Co.: Minneapolis, MN, USA, 1969.

23. Nesci, A.V.; Etcheverry, M.G. Control of Aspergillus growth and aflatoxin production using natural maize phytochemicals under different conditions of water activity. Pest Manag. Sci. Former. Pestic. Sci. 2006, 62, 775-784. [CrossRef]

24. Palumbo, J.D.; O'Keeffe, T.L.; Mahoney, N.E. Inhibition of ochratoxin A production and growth of Aspergillus species by phenolic antioxidant compounds. Mycopathologia 2007, 164, 241-248. [CrossRef]

25. Pani, G.; Scherm, B.; Azara, E.; Balmas, V.; Jahanshiri, Z.; Carta, P.; Fabbri, D.; Dettori, M.A.; Fadda, A.; Dessì, A. Natural and natural-like phenolic inhibitors of type B trichothecene in vitro production by the wheat (Triticum sp.) pathogen Fusarium culmorum. J. Agric. Food Chem. 2014, 62, 4969-4978. [CrossRef] [PubMed]

26. Žilius, M.; Ramanauskienè, K.; Briedis, V. Release of propolis phenolic acids from semisolid formulations and their penetration into the human skin in vitro. Evid. Based Complement. Altern. Med. 2013, 2013. [CrossRef]

27. Arnao, M.B.; Cano, A.; Acosta, M. Methods to measure the antioxidant activity in plant material. A comparative discussion. Free Radic. Res. 1999, 31, 89-96. [CrossRef] [PubMed]

28. Braumann, T. Determination of hydrophobic parameters by reversed-phase liquid chromatography: Theory, experimental techniques, and application in studies on quantitative structure-activity relationships. J. Chromatogr. A 1986, 373, 191-225. [CrossRef]

29. Kfoury, M.; Lounès-Hadj Sahraoui, A.; Bourdon, N.; Laruelle, F.; Fontaine, J.; Auezova, L.; Greige-Gerges, H.; Fourmentin, S. Solubility, photostability and antifungal activity of phenylpropanoids encapsulated in cyclodextrins. Food Chem. 2016, 196, 518-525. [CrossRef] [PubMed]

30. Divakar, S.; Maheswaran, M.M. Structural studies on inclusion compounds of $\beta$-cyclodextrin with some substituted phenols. J. Incl. Phenom. Mol. Recognit. Chem. 1997, 27, 113-126. [CrossRef]

31. Blackwell, B.A.; Miller, J.D.; Savard, M.E. Production of carbon 14-labeled fumonisin in liquid culture. J. AOAC Int. 1994, 77, 506-511. [CrossRef]

32. Balmas, V.; Delogu, G.; Sposito, S.; Rau, D.; Migheli, Q. Use of a complexation of tebuconazole with $\beta$-cyclodextrin for controlling foot and crown rot of durum wheat incited by Fusarium culmorum. J. Agric. Food Chem. 2006, 54, 480-484. [CrossRef] [PubMed]

33. Venturini, G.; Assante, G.; Toffolatti, S.L.; Vercesi, A. Pathogenicity variation in Fusarium verticillioides populations isolated from maize in Northern Italy. Mycoscience 2013, 54, 285-290. [CrossRef]

34. Ferrigo, D.; Raiola, A.; Bogialli, S.; Bortolini, C.; Tapparo, A.; Causin, R. In vitro production of fumonisins by Fusarium verticillioides under oxidative stress induced by $\mathrm{H}_{2} \mathrm{O}_{2}$. J. Agric. Food Chem. 2015, 63, 4879-4885. [CrossRef]

35. Lazzaro, I.; Susca, A.; Mulè, G.; Ritieni, A.; Ferracane, R.; Marocco, A.; Battilani, P. Effects of temperature and water activity on FUM2 and FUM21 gene expression and fumonisin B production in Fusarium verticillioides. Eur. J. Plant Pathol. 2012, 134, 685-695. [CrossRef]

36. Pfaffl, M.W. A new mathematical model for relative quantification in real-time RT-PCR. Nucleic Acids Res. 2001, 29, e45. [CrossRef] [PubMed]

37. Simon, P. Q-Gene: Processing quantitative real-time RT-PCR data. Bioinformatics 2003, 19, 1439-1440. [CrossRef] [PubMed]

38. Pizzolitto, R.P.; Jacquat, A.G.; Usseglio, V.L.; Achimón, F.; Cuello, A.E.; Zygadlo, J.A.; Dambolena, J.S. Quantitative-Structureactivity relationship study to predict the antifungal activity of essential oils against Fusarium verticillioides. Food Control 2020, 108, 106836. [CrossRef]

39. Pagnussatt, F.A.; Del Ponte, E.M.; Garda-Buffon, J.; Badiale-Furlong, E. Inhibition of Fusarium graminearum growth and mycotoxin production by phenolic extract from Spirulina sp. Pestic. Biochem. Physiol. 2014, 108, 21-26. [CrossRef] [PubMed]

40. Samapundo, S.; De Meulenaer, B.; Osei-Nimoh, D.; Lamboni, Y.; Debevere, J.; Devlieghere, F. Can phenolic compounds be used for the protection of corn from fungal invasion and mycotoxin contamination during storage? Food Microbiol. 2007, 24, 465-473. [CrossRef]

41. Zabka, M.; Pavela, R. Antifungal efficacy of some natural phenolic compounds against significant pathogenic and toxinogenic filamentous fungi. Chemosphere 2013, 93, 1051-1056. [CrossRef]

42. Gauthier, L.; Bonnin-Verdal, M.-N.; Marchegay, G.; Pinson-Gadais, L.; Ducos, C.; Richard-Forget, F.; Atanasova-Penichon, V. Fungal biotransformation of chlorogenic and caffeic acids by Fusarium graminearum: New insights in the contribution of phenolic acids to resistance to deoxynivalenol accumulation in cereals. Int. J. Food Microbiol. 2016, 221, 61-68. [CrossRef] 
43. Kulik, T.; Stuper-Szablewska, K.; Bilska, K.; Buśko, M.; Ostrowska-Kołodziejczak, A.; Załuski, D.; Perkowski, J. Trans-Cinnamic and chlorogenic acids affect the secondary metabolic profiles and ergosterol biosynthesis by Fusarium culmorum and F. graminearum sensu stricto. Toxins 2017, 9, 198. [CrossRef]

44. Atanasova-Penichon, V.; Bernillon, S.; Marchegay, G.; Lornac, A.; Pinson-Gadais, L.; Ponts, N.; Zehraoui, E.; Barreau, C.; Richard-Forget, F. Bioguided isolation, characterization, and biotransformation by Fusarium verticillioides of Maize kernel compounds that inhibit fumonisin production. Mol. Plant Microbe Interact. 2014, 27, 1148-1158. [CrossRef]

45. Pani, G.; Dessì, A.; Dallocchio, R.; Scherm, B.; Azara, E.; Delogu, G.; Migheli, Q. Natural phenolic inhibitors of trichothecene biosynthesis by the wheat fungal pathogen Fusarium culmorum: A computational insight into the structure-activity relationship. PLoS ONE 2016, 11, e0157316. [CrossRef]

46. Dambolena, J.S.; Zygadlo, J.A.; Rubinstein, H.R. Antifumonisin activity of natural phenolic compounds: A structure-propertyactivity relationship study. Int. J. Food Microbiol. 2011, 145, 140-146. [CrossRef]

47. Schöneberg, T.; Kibler, K.; Sulyok, M.; Musa, T.; Bucheli, T.D.; Mascher, F.; Bertossa, M.; Voegele, R.T.; Vogelgsang, S. Can plant phenolic compounds reduce fusarium growth and mycotoxin production in cereals? Food Addit. Contam. Part A 2018, 35, 2455-2470. [CrossRef] [PubMed]

48. Beekrum, S.; Govinden, R.; Padayachee, T.; Odhav, B. Naturally occurring phenols: A detoxification strategy for fumonisin B1. Food Addit. Contam. 2003, 20, 490-493. [CrossRef]

49. Ferruz, E.; Atanasova-Pénichon, V.; Bonnin-Verdal, M.-N.; Marchegay, G.; Pinson-Gadais, L.; Ducos, C.; Lorán, S.; Ariño, A.; Barreau, C.; Richard-Forget, F. Effects of phenolic acids on the growth and production of T-2 and HT-2 toxins by Fusarium langsethiae and F. sporotrichioides. Molecules 2016, 21, 449. [CrossRef] [PubMed]

50. Ferrochio, L.; Cendoya, E.; Farnochi, M.C.; Massad, W.; Ramirez, M.L. Evaluation of ability of ferulic acid to control growth and fumonisin production of Fusarium verticillioides and Fusarium proliferatum on maize based media. Int. J. Food Microbiol. 2013, 167, 215-220. [CrossRef]

51. Nesci, A.; Marín, S.; Etcheverry, M.; Sanchis, V. Natural maize phytochemicals for control of maize mycoflora and aflatoxigenic fungi. World Mycotoxin J. 2009, 2, 305-312. [CrossRef]

52. Dambolena, J.S.; López, A.G.; Cánepa, M.C.; Theumer, M.G.; Zygadlo, J.A.; Rubinstein, H.R. Inhibitory effect of cyclic terpenes (limonene, menthol, menthone and thymol) on Fusarium verticillioides MRC 826 growth and fumonisin B1 biosynthesis. Toxicon 2008, 51, 37-44. [CrossRef]

53. Jayashree, T.; Subramanyam, C. Antiaflatoxigenic activity of eugenol is due to inhibition of lipid peroxidation. Lett. Appl. Microbiol. 1999, 28, 179-183. [CrossRef] [PubMed]

54. Roleira, F.M.; Siquet, C.; Orrù, E.; Garrido, E.M.; Garrido, J.; Milhazes, N.; Podda, G.; Paiva-Martins, F.; Reis, S.; Carvalho, R.A. Lipophilic phenolic antioxidants: Correlation between antioxidant profile, partition coefficients and redox properties. Bioorg. Med. Chem. 2010, 18, 5816-5825. [CrossRef]

55. Appell, M.; Tu, Y.-S.; Compton, D.L.; Evans, K.O.; Wang, L.C. Quantitative structure-activity relationship study for prediction of antifungal properties of phenolic compounds. Struct. Chem. 2020, 31, 1621-1630. [CrossRef]

56. Yang, D.; Donovan, S.; Black, B.C.; Cheng, L.; Taylor, A.G. Relationships between compound lipophilicity on seed coat permeability and embryo uptake by soybean and corn. Seed Sci. Res. 2018, 28, 229-235. [CrossRef]

57. Menniti, A.M.; Gregori, R.; Neri, F. Activity of natural compounds on Fusarium verticillioides and fumonisin production in stored maize kernels. Int. J. Food Microbiol. 2010, 136, 304-309. [CrossRef] [PubMed]

58. Barz, W.; Hoesel, W. Metabolism and degradation of phenolic compounds in plants. In Biochemistry of Plant Phenolics; Springer: Cham, Switzerland, 1979; pp. 339-369.

59. Friedman, M.; Jürgens, H.S. Effect of PH on the stability of plant phenolic compounds. J. Agric. Food Chem. 2000, 48, 2101-2110. [CrossRef] [PubMed]

60. Guillén, F.; Evans, C.S. Anisaldehyde and veratraldehyde acting as redox cycling agents for $\mathrm{H}_{2} \mathrm{O}_{2}$ production by Pleurotus eryngii. Appl. Environ. Microbiol. 1994, 60, 2811-2817. [CrossRef]

61. Del Valle, E.M. Cyclodextrins and their uses: A review. Process Biochem. 2004, 39, 1033-1046. [CrossRef]

62. Kim, J.H.; Yu, J.; Mahoney, N.; Chan, K.L.; Molyneux, R.J.; Varga, J.; Bhatnagar, D.; Cleveland, T.E.; Nierman, W.C.; Campbell, B.C. Elucidation of the functional genomics of antioxidant-based inhibition of aflatoxin biosynthesis. Int. J. Food Microbiol. 2008, 122, 49-60. [CrossRef]

63. Boutigny, A.-L.; Barreau, C.; Atanasova-Penichon, V.; Verdal-Bonnin, M.-N.; Pinson-Gadais, L.; Richard-Forget, F. Ferulic acid, an efficient inhibitor of type B trichothecene biosynthesis and Tri gene expression in Fusarium liquid cultures. Mycol. Res. 2009, 113, 746-753. [CrossRef]

64. Proctor, R.H.; Desjardins, A.E.; Plattner, R.D.; Hohn, T.M. A polyketide synthase gene required for biosynthesis of fumonisin mycotoxins in Gibberella fujikuroi mating population A. Fungal Genet. Biol. 1999, 27, 100-112. [CrossRef] [PubMed]

65. Proctor, R.H.; Brown, D.W.; Plattner, R.D.; Desjardins, A.E. Co-Expression of 15 contiguous genes delineates a fumonisin biosynthetic gene cluster in Gibberella moniliformis. Fungal Genet. Biol. 2003, 38, 237-249. [CrossRef]

66. Desjardins, A.E.; Munkvold, G.P.; Plattner, R.D.; Proctor, R.H. FUM1-A gene required for fumonisin biosynthesis but not for maize ear rot and ear infection by Gibberella moniliformis in field tests. Mol. Plant Microbe Interact. 2002, 15, 1157-1164. [CrossRef]

67. Khosravi, A.R.; Shokri, H.; Mokhtari, A.R. Efficacy of Cuminum cyminum essential oil on FUM1 gene expression of fumonisinproducing Fusarium verticillioides strains. Avicenna J. Phytomed. 2015, 5, 34. [PubMed] 
68. Li, R.; Jiang, Z.-T. Chemical composition of the essential oil of Cuminum cyminum L. from China. Flavour Fragr. J. 2004, 19, 311-313. [CrossRef]

69. Etzerodt, T.; Maeda, K.; Nakajima, Y.; Laursen, B.; Fomsgaard, I.S.; Kimura, M. 2, 4-Dihydroxy-7-Methoxy-2H-1, 4-Benzoxazin-3 (4H)-One (DIMBOA) inhibits trichothecene production by Fusarium graminearum through suppression of Tri6 expression. Int. J. Food Microbiol. 2015, 214, 123-128. [CrossRef] [PubMed]

70. Li, T.; Jian, Q.; Chen, F.; Wang, Y.; Gong, L.; Duan, X.; Yang, B.; Jiang, Y. Influence of butylated hydroxyanisole on the growth, hyphal morphology, and the biosynthesis of fumonisins in Fusarium proliferatum. Front. Microbiol. 2016, 7. [CrossRef] [PubMed]

71. Medina, A.; Schmidt-Heydt, M.; Cárdenas-Chávez, D.L.; Parra, R.; Geisen, R.; Magan, N. Integrating Toxin gene expression, growth and fumonisin $\mathrm{B}_{1}$ and $\mathrm{B}_{2}$ production by a strain of Fusarium verticillioides under different environmental factors. J. $R$. Soc. Interface 2013, 10, 20130320. [CrossRef]

72. Desjardins, A.E. Fusarium Mycotoxins: Chemistry, Genetics, and Biology; American Phytopathological Society (APS Press): Saint Paul, MN, USA, 2006; ISBN 0-89054-335-6.

73. Cruz, A.; Marin, P.; Magan, N.; Gonzalez-Jaen, M.T. Combined effects of benomyl and environmental factors on growth and expression of the fumonisin biosynthetic genes FUM1 and FUM19 by Fusarium verticillioides. Int. J. Food Microbiol. 2014, 191, 17-23. [CrossRef] [PubMed]

74. López-Errasquín, E.; Vázquez, C.; Jiménez, M.; González-Jaén, M.T. Real-Time RT-PCR assay to quantify the expression of FUM1 and FUM19 genes from the fumonisin-producing Fusarium verticillioides. J. Microbiol. Methods 2007, 68, 312-317. [CrossRef] [PubMed]

75. Van Zyl, K.; Rose, L.J.; Viljoen, A. Fusarium verticillioides FUM1 and FUM19 gene expression in maize kernels during early infection. Physiol. Mol. Plant Pathol. 2019, 108, 101430. [CrossRef]

76. Sun, L.; Chen, X.; Gao, J.; Zhao, Y.; Liu, L.; Hou, Y.; Wang, L.; Huang, S. Effects of disruption of five FUM genes on fumonisin biosynthesis and pathogenicity in Fusarium proliferatum. Toxins 2019, 11, 327. [CrossRef]

77. Jurado, M.; Marín, P.; Callejas, C.; Moretti, A.; Vázquez, C.; González-Jaén, M.T. Genetic variability and fumonisin production by Fusarium proliferatum. Food Microbiol. 2010, 27, 50-57. [CrossRef] [PubMed]

78. De Oliveira Rocha, L.; Reis, G.M.; da Silva, V.N.; Braghini, R.; Teixeira, M.M.G.; Corrêa, B. Molecular Characterization and fumonisin production by Fusarium verticillioides isolated from corn grains of different geographic origins in Brazil. Int. J. Food Microbiol. 2011, 145, 9-21. [CrossRef] [PubMed]

79. Brown, D.W.; Butchko, R.A.E.; Busman, M.; Proctor, R.H. The Fusarium verticillioides FUM gene cluster encodes a Zn(II) ${ }_{2} \mathrm{Cys}_{6}$ protein that affects FUM gene expression and fumonisin production. Eukaryot. Cell 2007, 6, 1210-1218. [CrossRef] [PubMed]

80. Shim, W.-B.; Woloshuk, C.P. Regulation of fumonisin B1 biosynthesis and conidiation in Fusarium verticillioides by a cyclin-like (C-Type) gene, FCC1. Appl. Environ. Microbiol. 2001, 67, 1607-1612. [CrossRef] [PubMed]

81. Flaherty, J.E.; Woloshuk, C.P. Regulation of fumonisin biosynthesis in Fusarium verticillioides by a zinc binuclear cluster-type gene, ZFR1. Appl. Environ. Microbiol. 2004, 70, 2653-2659. [CrossRef] [PubMed]

82. Bluhm, B.H.; Woloshuk, C.P. Fck1, a C-Type cyclin-dependent kinase, interacts with Fcc1 to regulate development and secondary metabolism in Fusarium verticillioides. Fungal Genet. Biol. 2006, 43, 146-154. [CrossRef]

83. Kim, H.; Woloshuk, C.P. Role of AREA, a regulator of nitrogen metabolism, during colonization of maize kernels and fumonisin biosynthesis in Fusarium verticillioides. Fungal Genet. Biol. 2008, 45, 947-953. [CrossRef]

84. Myung, K.; Li, S.; Butchko, R.A.; Busman, M.; Proctor, R.H.; Abbas, H.K.; Calvo, A.M. FvVE1 Regulates biosynthesis of the mycotoxins fumonisins and fusarins in Fusarium verticillioides. J. Agric. Food Chem. 2009, 57, 5089-5094. [CrossRef] 